\title{
A APRENDIZAGEM DAS ORGANIZAÇÕES GERADA PELAS PRÁTICAS FORMAIS NO
} AMBIENTE DE TRABALHO

\begin{abstract}
ÂNGELA FRANÇA VERSIANI
Doutora em Administração pela Faculdade de Economia, Administração e Contabilidade da Universidade de São Paulo (FEA-USP).

Professora do Programa de Pós-Graduação em Administração da Pontifícia Universidade Católica de Minas Gerais (PUC-MG).
\end{abstract} Avenida Itaú, 525, Dom Cabral, Belo Horizonte - MG - Brasil - CEP 30535-012

E-mail:versiani@pucminas.br

\section{CLAUDEMIR YOSCHIHIRO ORIBE}

Mestre em Administração pelo Departamento de Administração da Pontifícia Universidade Católica de Minas Gerais (PUC-MG).

Sócio-consultor e diretor de projetos da Qualypro Tecnologia Ltda. Rua Norberto Mayer, 626, sala 201, Eldorado, Contagem - MG - Brasil - CEP 32315-100

E-mail: claudemir@qualypro.com.br

\section{SERGIO FERNANDO LOUREIRO REZENDE}

Doutor em Marketing pela Management School da Lancaster University.

Professor do Programa de Pós-Graduação em Administração

da Pontifícia Universidade Católica de Minas Gerais (PUC-MG).

Avenida Itaú, 525, Dom Cabral, Belo Horizonte - MG - Brasil - CEP 30535-012

E-mail: sflrezende@gmail.com

Este artigo pode ser copiado, distribuído, exibido, transmitido ou adaptado desde que citados, de forma clara e explícita, o nome da revista, a edição, o ano, e as páginas nas quais o artigo foi publicado originalmente, mas sem sugerir que a RAM endosse a reutilização do artigo. Esse termo de licenciamento deve ser explicitado para os casos de reutilização ou distribuição para terceiros. Não é permitido o uso para fins comerciais. 


\section{RESUMO}

Este artigo tem por objetivo avaliar em que medida práticas formais instituídas no ambiente de trabalho contribuem para a aprendizagem organizacional. $\mathrm{O}$ quadro teórico baseia-se no reconhecimento de que a adaptação das empresas ao ambiente implica a absorção do conhecimento dos indivíduos em propriedades coletivas legitimamente reconhecidas e incorporadas nas suas práticas. A aprendizagem se dá no momento em que as empresas, ao lidarem com o ambiente, aproveitam os recursos de que dispõem e concomitantemente exploram novas oportunidades, mudando as práticas correntes. O método de análise de solução sistemática de problemas é reconhecido como uma das práticas formais mais recomendadas para promover aprendizagem organizacional. Entretanto, se, por um lado, constata-se a exaltação de tal método para gerar aprendizado, por outro, a literatura se ressente de uma avaliação mais crítica. Isto é, há escassez de pesquisa empírica que visa verificar a sua real contribuição em promover a aprendizagem organizacional. Desse modo, verifica-se uma lacuna entre recomendações práticas e sustentação teórica de tais recomendações. Este artigo, ao indagar em que medida os métodos de solução sistemática de problemas contribuem para a aprendizagem organizacional, tem por principal contribuição esclarecer os seus efeitos nas organizações que os utilizam. Assim, focalizou-se o Masp, um dos métodos de solução sistemática de problemas mais difundidos no Brasil. Para proceder a essa avaliação, considerou-se que aprendizagem organizacional é composta de quatro dimensões: aquisição do conhecimento, distribuição e interpretação da informação e memória organizacional. O foco da pesquisa foi verificar, em uma pesquisa quantitativa junto a três diferentes organizações, como o Masp relaciona-se a tais dimensões. Mais especificamente, buscou-se identificar quais são as dimensões e os tipos de aprendizado sustentados pelo Masp. Os testes estatísticos revelaram que a utilização do Masp contribui para todas as dimensões da aprendizagem organizacional, ou seja, aquisição do conhecimento, distribuição e interpretação da informação e memória organizacional. Contudo, tal aprendizagem tende a se restringir frequentemente às correções em rotinas, $\mathrm{o}$ 
que significa que a utilização do método em si não é capaz de gerar aprendizados mais profundos. A profundidade do aprendizado parece correlacionar-se mais fortemente aos fatores contextuais das organizações.

\section{PALAVRAS-CHAVE}

Aprendizagem organizacional; Práticas formais de aprendizagem; Masp; Método de solução sistemática de problemas; Aprendizagem no ambiente de trabalho.

\section{INTRODUÇÃO}

As discussões sobre como as empresas se adaptam ao ambiente são fortemente referenciadas nas mais diversas perspectivas teóricas dos estudos organizacionais (PAWLOWSKY, 2003; SCOTT, I998). No conjunto dessas perspectivas, sobressai a ideia de que o alinhamento das empresas com o ambiente é resultado de sua aprendizagem (MILLER, I996; MIRVIS; MARYLAND, I996). Esse entendimento tem se fortalecido com a consolidação da literatura sobre aprendizagem organizacional, cuja maior contribuição está em destacar a importância do fluxo de conhecimento na mudança do comportamento das organizações (CASEY; GOLDMAN, 20IO; VERSIANI; FISCHER, 2008).

Na perspectiva da aprendizagem organizacional, a adaptação das empresas ao ambiente implica a absorção do conhecimento dos indivíduos em propriedades coletivas legitimamente reconhecidas e incorporadas nas suas práticas (GRANT, I996; NONAKA; TOYOAMA; NAGATA, 2000; SPENDER, I996; TAKAHASHI; FISCHER, 2009). A aprendizagem se dá no momento em que, ao lidarem com o ambiente, as empresas procuram aproveitar os recursos de que dispõem. Concomitantemente, são capazes de explorar oportunidades antes não vislumbradas, mudando as práticas correntes (LEVITT; MARCH, I99I) e desencadeando melhorias organizacionais (CASEY, 2005; GARVIN, I993).

Embora haja consenso de que a aprendizagem organizacional seja a base de sustentação necessária à mudança que promove adaptação ambiental, a questão de como promover a aprendizagem ainda parece não estar suficientemente respondida (SMITH; ARAUJO, 200I), principalmente no que diz respeito às práticas formais capazes de fomentá-la (ANTONELLO, 2005; CASEY, 2005). Divulga-se que as propostas de intervenções para promover a aprendizagem não têm logrado êxito (MIRVIS; MARYLAND, I996; SMITH; ARAUJO, 200I). Isso ocorre porque as abordagens prescritivas próprias de uma orientação para 
a ação se assentam muito mais em relatos inspirados de como as intervenções funcionam do que na avaliação crítica dos efeitos de tais intervenções, próprias da análise do trabalho acadêmico tradicional (SMITH; ARAUJO, 200I).

No que diz respeito especificamente aos métodos de solução sistemática de problemas, considerados como uma das práticas formais mais potentes na geração do aprendizado organizacional (DIBELLA; NEVIS, I998; GARVIN, I993; KETELHÖHN, I995; LEONARD-BARTON, I992), a literatura ressente-se de avaliações mais aprofundadas. No Brasil, as pesquisas que envolvem a apreciação desses métodos, como as de Salviato (I999), Martins (2002), Guerra (2002) e Magalhães (2005), estão voltadas basicamente para compreender as variações do método em si. Uma exceção é o trabalho de Witt (2002), que abordou a contribuição dos métodos de solução sistemática de problemas na aprendizagem organizacional. Contudo, conforme reconhecido pela própria autora, a principal contribuição de seu estudo está em identificar novas práticas pedagógicas de aplicação do método.

A literatura tem procurado, sobretudo, descrever os métodos de solução sistemática de problemas visando à orientação de profissionais em sua utilização empírica (CAMPOS, 2004; SCHOLTES, 2002), sem proceder a uma avaliação no que diz respeito aos benefícios e resultados alcançados no âmbito do comportamento das organizações. De um lado, há um vácuo no que se refere ao conhecimento sobre os impactos causados pelos métodos de solução sistemática de problemas no aprendizado organizacional e, de outro, um conjunto de prescrições e recomendações empíricas, exaltando a sua utilização para que sejam promovidas mudanças organizacionais. Desse modo, existe uma lacuna entre recomendações práticas e sustentação teórica de tais recomendações.

Visando avançar pesquisas que contribuam para diminuir essa lacuna, realizamos uma pesquisa cujo objetivo foi avaliar em que medida o Masp, um método de análise sistemática de solução de problemas, contribui para a aprendizagem organizacional. Pesquisamos três empresas que utilizam o Masp em seus processos de melhorias organizacionais, mediante a adoção do recorte metodológico do tipo quantitativo.

O foco de análise da pesquisa foi identificar as dimensões e os tipos de aprendizado sustentados pelo Masp. Os resultados da análise demonstraram que, de maneira geral, esse método contribui em todas as quatro dimensões da aprendizagem organizacional, ou seja, aquisição do conhecimento, distribuição e interpretação da informação e memória organizacional. No entanto, o tipo de aprendizagem organizacional tende a se restringir às correções em rotinas, sendo associado à aquisição de técnicas específicas identificadas com o aprendizado de laço único. Verificamos que a utilização do Masp em si não foi capaz de gerar 
aprendizados mais profundos, como o aprendizado de laço duplo, o qual parece se correlacionar mais fortemente com as variáveis contextuais das organizações.

Visando discutir essas conclusões, desenvolvemos o presente artigo em quatro seções, incluindo esta introdução. Na segunda seção, o argumento teórico é construído, mostrando como a solução de problemas por meio da aplicação do Masp relaciona-se ao aprendizado organizacional. Na terceira seção, discorremos sobre o quadro metodológico que fundamentou a condução de nossa pesquisa. E, por fim, na quarta e quinta seções, os resultados e conclusões são descritos e discutidos à luz de suas contribuições teóricas e empíricas.

\section{A SOLUÇÃo de PROBlemas e o APRENDIZADO ORGANIZACIONAL}

A análise da literatura sobre a aprendizagem das organizações sugere que o debate iniciado na década de I990 sobre a confusão em relação ao conceito aprendizado organizacional avançou com o reconhecimento desse construto teórico (CHIVA; ALEGRE, 2005). Promoveu-se o entendimento de que tal construto é tradicionalmente abordado em dois diferentes quadros paradigmáticos. De um lado, o quadro funcionalista e, de outro, o interpretativista.

O quadro funcionalista é identificado com a perspectiva mentalista (MARSHALL, 2008), técnica ou gerencial (ELKJAER, 200I), a qual concebe o aprendizado a partir da cognição, considerando-o como algo que pode ser categorizado e classificado. Já no quadro interpretativista situam-se as abordagens de comunidade ou das práticas situadas (GHERARDI, 2000), as quais postulam que o aprendizado é emergente ao contexto em que práticas específicas ocorrem. Embora seja evidente o antagonismo ontológico e epistemológico desses quadros, consubstanciou-se a ideia de que o construto teórico "aprendizagem organizacional" fundamenta-se em três eixos conceituais (CHIVA; ALEGRE, 2005; MARSHALL, 2008).

O primeiro eixo desse alicerce conceitual refere-se ao entendimento de que a aprendizagem organizacional diz respeito aos vários processos relacionados ao conhecimento, que englobam desde a geração, interpretação, uso e armazenamento até o seu descarte (KIM, I993; HEDBERG, I98I; NONAKA; TAKEUCHI, I997). O segundo eixo compreende a noção de transformação. Isto é, a aprendizagem organizacional implica mudança nos modelos mentais e no comportamento organizacional (HUYSMAN, 200I; PRANGE, 200I). Finalmente, o terceiro eixo aborda as camadas que o compõem, ou seja, a inter-relação dos níveis em que a aprendizagem flui, o nível do indivíduo, do grupo e da organização propriamente dita. 
Cabe destacar que esse conjunto conceitual tem sido colocado à prova, com alguns estudos buscando sustentá-lo empiricamente, mediante o teste de sua validade. Um exemplo dessa tentativa é a pesquisa de Templeton, Lewis e Snyder (2002). Essa pesquisa validou estatisticamente o construto da aprendizagem organizacional, demonstrando que se apoia nas quatro dimensões relacionadas, a saber: aquisição do conhecimento, distribuição e interpretação da informação e memória organizacional. Essa validação disponibilizou um instrumento para avaliar o aprendizado relacionado ao comportamento das organizações e ratificou a proposição sustentada por autores das mais diversas perspectivas paradigmáticas de que o aprendizado pressupõe a reflexão sobre as práticas do ambiente de trabalho.

Entre tais práticas, sobressaem as formais, ou seja, os programas e métodos instituídos pelas empresas para promover melhorias ou mudanças organizacionais. O método sistemático de solução de problemas tem sido amplamente recomendado para esse fim (DIBELLA; NEVIS, I998; GARVIN, I993; KETELHÖHN, I995; LEONARD-BARTON, I992), sendo o Masp um dos métodos mais difundidos no Brasil (ALVAREZ, I996; GOMES, 2004). Cabe ressaltar que o Masp é derivado do método de origem japonesa denominado QC-Story, que por sua vez é um desdobramento metodológico do ciclo PDCA, cuja origem remonta ao movimento de qualidade total introduzido no Japão, na década de I950. O QC-Story tornou-se um método de contornos prescritivos aplicados a quaisquer problemas de mudança e melhorias organizacionais (ALVAREZ, I996).

A introdução do QC-Story no Brasil e sua divulgação nas empresas foram feitas por Campos (2004), que adaptou sua versão ao contexto brasileiro, denominando-a de Masp. O Masp é um dos métodos de solução sistemática de problemas atualmente mais recomendados pela União Brasileira de Qualidade (ORIBE, 2008) para o desenvolvimento de projetos de melhoria da qualidade. Desse modo, ele é a "versão brasileira do método japonês denominado de 'QC-Story" (CAMPOS, 2004, p. 238). e se aplica aos problemas classificados como estruturados (PERPÉTUO; TEIXEIRA, 200I), decorrentes de causas comuns (DEMING, I990) cujas soluções sejam desconhecidas (HOSOTANI, I992) e envolvam reparação (NICKOLS, 2004) ou melhoria de desempenho (SMITH, 2000).

A aplicação do Masp perfaz um ciclo composto de oito etapas ou processos. O processo ou etapa de número I, denominado de identificação do problema, inicia-se com os indivíduos emitindo suas opiniões pessoais sobre determinada situação-problemática para chegar a uma informação válida sobre o que constitui o problema a ser solucionado (KETELHÖHN, I995). Na segunda etapa, chamada de observação, averiguam-se as condições em que o problema ocorre e suas características sob ampla gama de pontos de vista (HOSOTANI, I992; 
KUME, I992; PARKER, I995). Na etapa 3 realiza-se a análise, tentando descobrir as causas do problema a partir de dados empíricos comprováveis (HOSOTANI, I992).

Descobertos quais são os fatores que influenciam os resultados desejados, busca-se controlar esses fatores no processo 4 . O processo 4 - plano de ação consiste em encontrar as formas de eliminar as causas dos problemas. Para o auxílio nessa tarefa, Campos (2004) sugere que o plano de ação seja elaborado tomando-se por base a escolha de uma alternativa de solução entre várias possíveis, definindo-se ações corretivas apropriadas, respeitando-se requisitos de prazos e custos.

A quinta etapa - ou processo 5 - é chamada de ação e diz respeito à execução das tarefas e atividades previstas anteriormente, o que implica a concentração das ações nos focos predeterminados. A comparação dos resultados obtidos com a meta estabelecida é tratada no sexto processo - ou etapa 6 - conhecido como verificação. A verificação deve incluir a identificação de eventuais efeitos secundários (CAMPOS, 2004), colaterais (HOSOTANI, I992) ou adversos (PARKER, I995).

Se os resultados demonstraram que os objetivos e metas foram atingidos, então as etapas seguintes devem ser orientadas para a consolidação desses resultados ou mesmo para reiniciar um novo ciclo de melhorias no futuro. Em consequência, tem-se o sétimo processo - ou etapa 7 - do Masp, a padronização de procedimentos. No processo ou etapa 7 , instituem-se novos métodos de trabalho registrando-os em documentos e mediante treinamento.

No oitavo processo, ou etapa 8 - a conclusão -, finaliza-se a aplicação do Masp. Os objetivos da conclusão são basicamente rever todo o processo de solução de problemas e planejar os trabalhos futuros (KUME, I992). A etapa e o método encerram-se com uma reflexão sobre o desempenho da equipe na utilização do método. Procura-se identificar pontos de melhoria no comportamento ou nas habilidades das pessoas, que poderiam aumentar a performance em aplicações posteriores.

É importante salientar que, na base dessas oito etapas, está a concepção de que o Masp possibilita à organização criar um terreno fértil para a mudança, mediante um estilo específico de aprendizagem. Esse estilo denominado de estilo de correção ocorre quando a organização, ao constatar problemas em suas operações, parte do conhecimento gerado internamente, usando-o de maneira incremental para fazer ajustes nos produtos e sistemas existentes (DIBELLA; NEVIS, I998; GARVIN, I993; KETELHÖHN, I995; LEONARD-BARTON, I992).

Na perspectiva de Argyris e Schön (I978), o estilo de correção tende a estar mais próximo do aprendizado de laço simples, porque focaliza melhorias nas rotinas estabelecidas dentro dos limites das estruturas existentes na organização 
(CHILD, I997). Deve ser destacado que, apesar de o estilo de correção ser identificado mais com o aprendizado de laço simples, é plausível a suposição de que correções de erros possam também redirecionar práticas em novas concepções e sistemas. Daí a possibilidade de o Masp desencadear aprendizados mais profundos, como aquele denominado de laço duplo.

Conforme informam Argyris e Schön (I978), o aprendizado de laço duplo consiste não apenas na mudança das normas organizacionais, mas também num particular tipo de questionamento em direção àquelas normas. Nesse sentido, salienta a importância da cognição e sua inter-relação com a prática, chamando a atenção para o caráter holístico do pensamento e ação. Esse caráter parece estar presente no Masp, uma vez que tal método incentiva seus usuários a refletir sobre suas práticas e redirecioná-las.

Na aplicação do Masp, as pessoas devem coletar dados, analisá-los para obter informação válida e disseminá-la, gerar conhecimentos sobre possíveis soluções, transferir esse conhecimento aos demais e torná-lo disponível para que seja novamente utilizado. Na medida em que as etapas do Masp se sucedem e o projeto avança, o conhecimento individual vai se expandindo, podendo atingir o nível da organização. Ao possibilitar essa dinâmica, o Masp permite equilibrar cognição com comportamento.

Se, por um lado, a proposição teórica de que o Masp é um dos mecanismos capazes de gerar aprendizado organizacional possui coerência teórica, por outro é necessário verificá-la na realidade concreta das empresas que o utilizam em seus processos organizacionais. Com essa verificação podemos avaliar suas contribuições para a aprendizagem organizacional. A seguir detalhamos a metodologia que realizou tal avaliação.

\section{METODOLOGIA}

A pesquisa aqui relatada tem por objetivo avaliar em que medida o Masp contribui para a aprendizagem organizacional. Para tanto, empregamos a estratégia de pesquisa do tipo descritiva de natureza quantitativa. Esse tipo de pesquisa é a mais adequada ao objetivo proposto, uma vez que permite aferir medições sobre o quanto e em que proporção há consenso de opiniões em relação a uma determinada realidade (FREUND; SIMON, 2000; TRIOLA, I999). Procuramos identificar quais são as dimensões e os tipos de aprendizado sustentados pelo Masp com uma pesquisa de caráter dedutivo.

Para compor o desenho metodológico, tomamos como base a referência do modelo de Templeton, Lewis e Snyder (2002) e aquelas que contemplam 
as etapas e/ou processos de aplicação do Masp. Essa escolha se deve ao fato de que esses autores representam os poucos estudiosos que validaram estatisticamente o construto da aprendizagem organizacional e pela consistência da validação. Embora essa validação tenha sido realizada especificamente no cenário das empresas de tecnologia da informação, tem sido referenciada em diferentes âmbitos da pesquisa em aprendizagem organizacional, tais como, mais recentemente, nas pesquisas de Santos-Vijande, López-Sanchez e Trespalacios (20I2) ou de Martínez-León e Martínez-García (20II).

Neste ponto é importante ressaltar que não pretendíamos replicar o modelo de Templeton, Lewis e Snyder (2002) na íntegra, validando-o no contexto brasileiro, e sim utilizá-lo como referência sobre a comprovação empírica do construto da aprendizagem organizacional. Trata-se de uma escolha necessária à composição do quadro dedutivo de pesquisa próprio de investigações científicas de caráter quantitativo.

Para a composição desse quadro, tomamos como referência os 46 critérios abordados no modelo de Templeton, Lewis e Snyder (2002), que definem a aprendizagem organizacional como um processo composto das quatro dimensões já mencionadas. Após a tradução desses critérios feita pelos autores do artigo e revisada por especialista da língua inglesa, eles foram plotados em uma matriz conjugada com os oito processos ou etapas do Masp e seus 28 passos (Quadro I).

Como pode ser visto nessa matriz, cruzamos as dimensões da aprendizagem organizacional com as etapas do Masp. A intenção desse cruzamento foi visualizar significados convergentes entre as dimensões da aprendizagem organizacional e dos processos do Masp para derivar as perguntas que seriam elaboradas, suportando as variáveis submetidas às estatísticas descritivas e aos testes estatísticos. Como resultado do cruzamento, identificamos 20 elementos correspondentes que formavam as dimensões da aprendizagem organizacional e dos processos e passos do Masp (Quadro I).

Tendo em vista essa relação, 20 questões foram elaboradas para compor o questionário. No sentido de garantir a validade de seu conteúdo, as questões foram submetidas à análise de três professores especialistas no tema, que responderam se elas eram essenciais, importantes ou não relevantes para a pesquisa. Seus comentários e sugestões foram analisados e considerados para a confecção da versão final do questionário. 


\section{QUADRO I}

IDENTIFICAÇÃO DOS 20 ELEMENTOS CORRESPONDENTES ENTRE O MODELO DE APRENDIZAGEM E AS ETAPAS DO MASP

\begin{tabular}{|c|c|c|c|c|c|c|c|c|c|c|c|c|c|c|c|c|c|c|c|c|c|c|}
\hline \multirow{3}{*}{\multicolumn{3}{|c|}{$\begin{array}{r}\text { CONSTRUTO } \rightarrow \\
\text { SUBCONSTRUTO } \rightarrow \\
\text { CÓDIGO } \rightarrow\end{array}$}} & \multicolumn{7}{|c|}{ AQUISIÇÃO DE CONHECIMENTO } & \multicolumn{5}{|c|}{ DISTRIBUIÇÃO DA INFORMAÇÃO } & \multicolumn{5}{|c|}{ INTERPRETAÇÃO DA INFORMAÇÃO } & \multicolumn{3}{|c|}{$\begin{array}{c}\text { MEMÓRIA } \\
\text { ORGANIZACIONAL }\end{array}$} \\
\hline & & & \multicolumn{2}{|c|}{$\begin{array}{l}\text { APRENDIZADO } \\
\text { EXPERIMENTAL }\end{array}$} & \multirow{2}{*}{ 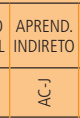 } & \multicolumn{4}{|c|}{ BUSCA E ALERTA } & \multicolumn{2}{|c|}{$\begin{array}{l}\text { LOGISTICA DO } \\
\text { CONHECIMENTO }\end{array}$} & \multicolumn{3}{|c|}{$\begin{array}{c}\text { DISSEMINAÇÄO } \\
\text { DO } \\
\text { CONHECIMENTO } \\
\end{array}$} & \multicolumn{2}{|c|}{$\begin{array}{c}\text { MAPAS } \\
\text { COGNITIVOS }\end{array}$} & \multirow{2}{*}{$\begin{array}{c}\begin{array}{c}\text { SOBRE } \\
\text { CARGA }\end{array} \\
\doteq\end{array}$} & \multicolumn{2}{|c|}{ DESAPRENDIZADO } & \multicolumn{2}{|c|}{\begin{tabular}{|c|} 
ARMAZ. E \\
RECUP. DE \\
INFORMAÇÃOO \\
\end{tabular}} & \multirow{2}{*}{ 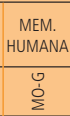 } \\
\hline & & & Ü. & 岁 & & ن̀ं & $\begin{array}{l}0 \\
\dot{u} \\
\dot{\&} \\
\end{array}$ & 品 & $\dddot{u}$ & $\stackrel{\frac{T}{1}}{0}$ & $\stackrel{\infty}{\dot{亠}}$ & $\frac{u}{\square}$ & $\frac{0}{0}$ & 岀 & $\stackrel{\varrho}{=}$ & $\stackrel{ }{=}$ & & $\stackrel{I}{=}$ & 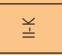 & $\sum_{\substack{1 \\
\vdots}}^{\circ}$ & $\sum_{i}^{\infty}$ & \\
\hline  & ڤ̊ & 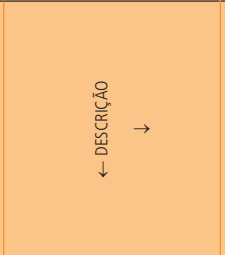 & 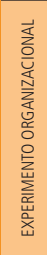 & 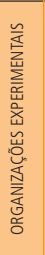 & 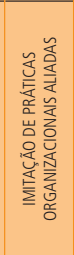 & 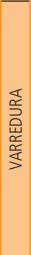 & 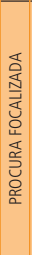 & 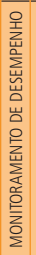 & 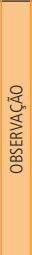 &  & 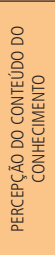 & 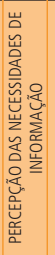 & 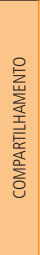 & 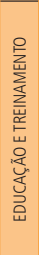 & 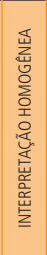 & 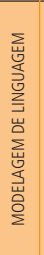 & 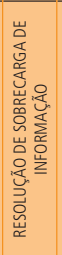 & 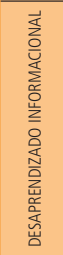 & 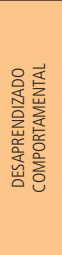 & 点 & $\begin{array}{l}\text { 온 } \\
\text { 㟧 } \\
\text { 总 } \\
\text { ॠ }\end{array}$ & 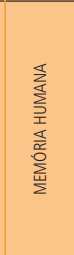 \\
\hline \multirow{5}{*}{ 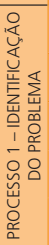 } & $1^{\circ}$ & Escolha do problema & & & & $x$ & $x$ & & & & & & & & & & & & & & & \\
\hline & $2^{\circ}$ & Histórico do problema & & & & & $x$ & & & & & $x$ & & & & $x$ & & & & & $x$ & \\
\hline & $3^{\circ}$ & $\begin{array}{l}\text { Mostrar perdas atuais e } \\
\text { ganhos viáveis }\end{array}$ & & & & & & $x$ & & & & & $x$ & & & $x$ & & & & & & \\
\hline & $4^{\circ}$ & Fazer a análise de Pareto & & & & & & & & & $x$ & & & & $x$ & $x$ & $x$ & & & & & \\
\hline & $5^{\circ}$ & Nomear responsáveis & & & & & & & & & & & & & & & & & & & & \\
\hline \multirow{3}{*}{  } & $1^{\circ}$ & $\begin{array}{l}\text { Descoberta das } \\
\text { caracteristicas do problema } \\
\text { por meio de coleta de dados }\end{array}$ & & & & & & & & & & $\mathrm{x}$ & & & & & & & & & $\mathrm{x}$ & \\
\hline & $2^{\circ}$ & $\begin{array}{l}\text { Descoberta das caracteristicas } \\
\text { do problema por meio de } \\
\text { observação no local }\end{array}$ & & & & & & & & & & & & & & & & & & & & \\
\hline & $3^{\circ}$ & $\begin{array}{l}\text { Cronograma, orçamento } \\
\text { e meta }\end{array}$ & & & & & & & & & & & $x$ & & $x$ & $x$ & & & & & & \\
\hline \multirow{5}{*}{ 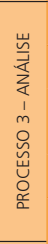 } & $1^{\circ}$ & $\begin{array}{l}\text { Definição das causas } \\
\text { influentes }\end{array}$ & & $x$ & & $x$ & $x$ & & & $x$ & & $x$ & & & & & & & & & & \\
\hline & $2^{\circ}$ & $\begin{array}{l}\text { Escolha das causas mais } \\
\text { prováveis (hipóteses) }\end{array}$ & & & & & $x$ & & & & & & & & & $x$ & $x$ & & & & & \\
\hline & $3^{\circ}$ & $\begin{array}{l}\text { Análise das causas mais } \\
\text { prováveis (verificação das } \\
\text { hipóteses) }\end{array}$ & & & & & & & & & $x$ & & & & & $x$ & & & & & & \\
\hline & & $\begin{array}{l}\text { Houve confirmação de } \\
\text { alguma causa mais provável? }\end{array}$ & & & & & & & & & & & & & & & & & & & & \\
\hline & & $\begin{array}{l}\text { Teste de consistência da } \\
\text { causa fundamental }\end{array}$ & $x$ & & & & & & & & & & & & & & & & & & & \\
\hline \multirow{2}{*}{ 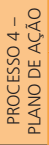 } & $1^{\circ}$ & $\begin{array}{l}\text { Elaboraçẫo da estratégia } \\
\text { de açâo }\end{array}$ & & $x$ & $x$ & & & & & & & & & & & & $x$ & & & & & \\
\hline & $2^{\circ}$ & $\begin{array}{l}\text { Elaboração do plano de } \\
\text { ação para o bloqueio e } \\
\text { revisão do cronograma e } \\
\text { orçamento final }\end{array}$ & & & & & & & & & & & $x$ & & & $x$ & & & & & & \\
\hline \multirow{2}{*}{ 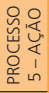 } & $1^{\circ}$ & Treinamento & & & & & & & & & & & & $x$ & & & & & $x$ & & & \\
\hline & $2^{\circ}$ & Execuçẫo da ação & & & & & & & & & & & & & & & & & & & & \\
\hline \multirow{4}{*}{ 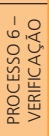 } & $1^{\circ}$ & Comparação dos resultados & $\mathrm{x}$ & & & & & $\mathrm{X}$ & & & & & & & & $\mathrm{x}$ & & & & & & \\
\hline & $2^{\circ}$ & $\begin{array}{l}\text { Listagem dos efeitos } \\
\text { secundários }\end{array}$ & & & & $x$ & $x$ & & $x$ & & & & & & & & & & & & & \\
\hline & $3^{\circ}$ & $\begin{array}{l}\text { Verificação da continuidade } \\
\text { ou não do problema }\end{array}$ & & & & & & & & & & & & & & & & & & & & \\
\hline & & O bloqueio foi efetivo? & & & & & & & & & & & & & & & & & & & & \\
\hline \multirow{4}{*}{ 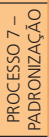 } & $1^{\circ}$ & $\begin{array}{l}\text { Elaboração ou alteraçâo } \\
\text { do padrão }\end{array}$ & & & & & & & & & & & $x$ & & & & & $x$ & & & & \\
\hline & $2^{\circ}$ & Comunicação & & & & & & & & & & & $x$ & & & & & & & $x$ & $x$ & \\
\hline & $3^{\circ}$ & Educação e treinamento & & & & & & & & & & & $x$ & & & & & & $x$ & & & \\
\hline & $4^{\circ}$ & $\begin{array}{l}\text { Acompanhamento da } \\
\text { utilização do padrão }\end{array}$ & & & & & & $x$ & & & & & & & & & & & $x$ & & & \\
\hline $\begin{array}{ll}1 & 0 \\
\infty & 0 \\
0 & \leqslant\end{array}$ & $1^{\circ}$ & $\begin{array}{l}\text { Relação dos problemas } \\
\text { remanescentes }\end{array}$ & & & & $x$ & $x$ & & $x$ & & & & & & & & & & $x$ & & & \\
\hline 岃艺 & $\begin{array}{l}2^{\circ} \\
(*)\end{array}$ & $\begin{array}{l}\text { Planejamento do ataque aos } \\
\text { problemas }\end{array}$ & & & & & & & & & & & & & & & & & $x$ & & & \\
\hline$\approx u$ & $3^{\circ}$ & Reflexāo & & & & $\mathrm{x}$ & & & & & & & & & & & & & & & & $x$ \\
\hline
\end{tabular}

Fonte: Elaborado pelos autores. 
Cabe informar que cada questão continha uma escala de io pontos para marcação do grau de concordância do respondente conforme sua percepção em relação ao Masp. A escala caminhava do ponto I discordância total para o ponto Io concordância total. Também havia a opção "não sei" em relação aos pontos da escala.

Ao optarmos pela escala de io pontos, pretendíamos reduzir a probabilidade de haver tendência artificial das médias das variáveis. Quando a escala é pequena, a média tende a sofrer influência, caminhando para o nível moderado, perdendo-se, com isso, a qualidade da informação. Para minimizar esse efeito, escalas mais amplas são recomendadas (TRIOLA, I999), sugestão seguida na elaboração do questionário. Desse modo, o questionário visou medir a percepção dos membros organizacionais sobre as atividades de aprendizagem propiciadas pelo Masp.

O levantamento dos dados foi realizado, em 2008, por meio de survey aplicado a três empresas distintas. Para participar do estudo, estipulamos que as unidades de análise deveriam ser empresas de grande porte e tivessem experiência de no mínimo três anos no uso do Masp. As empresas com aceites de participação nesta pesquisa atuam nos setores de telecomunicações, mineração e celulose. Atendendo a seus pedidos, foram omitidas suas identificações, sendo denominadas, neste trabalho, de empresa I, empresa 2 e empresa 3.

No que diz respeito à seleção das unidades de observação, a amostra de cada empresa foi não probabilística, sendo selecionada por critérios de conveniência. Procuramos endereçar os questionários aos gerentes e membros de equipes que tivessem algum contato com o Masp, ou seja, pessoas que utilizavam o Masp pessoalmente ou que acompanhavam grupos que o utilizavam. Os questionários foram disponibilizados em dois formatos: em papel ou formulário eletrônico para acesso via internet, possibilitando às empresas a escolha pelo formato que desejassem, bem como a divulgação da pesquisa e a entrega dos questionários aos respondentes. Esse procedimento foi adotado visando às relações cordiais com as empresas, dadas as suas exigências para participarem da pesquisa.

Como consequência das limitações do campo de pesquisa, houve diferenciações na forma e quantidade de questionários distribuídos por empresa, embora tenham sido garantidas a não identificação dos respondentes e a aleatoriedade das amostras. A empresa I optou por divulgar o endereço eletrônico onde o questionário estava disponível. Já as empresas 2 e 3 optaram por distribuir o questionário em papel. Os questionários, em número de I20 para a empresa 2, foram respondidos por 54 pessoas. Na empresa 3, foram distribuídos 60 questionários, respondidos por 4I pessoas. Na empresa I, o questionário foi respondido por 88 pessoas. Dessa forma, obteve-se a amostra total, entre as três empresas, de 183 questionários devidamente respondidos. 
Uma vez obtidos os dados, utilizamos para o processamento das análises e testes estatísticos o software Statistical Package for the Social Science (SPSS) versão II. Num primeiro momento, para o conjunto dos I83 respondentes, foram calculadas as estatísticas descritivas das variáveis, sendo escolhida a média aritmética como medida de posição, uma vez que representa bem os dados e tem a vantagem de ser uma medida que leva em conta todos os valores (TRIOLA, I999). Para medir a variabilidade dos dados, calculou-se o desvio padrão, lembrando que quanto mais os dados se dispersam, o valor do desvio padrão aumenta. E para conhecer o menor e o maior grau de concordância atribuído a cada um dos quesitos, foram apresentados os valores mínimos e máximos, respectivamente. Registramos, também, o número total de observações válidas, ou seja, desconsideramos as respostas "não sei" e as questões não respondidas, deixadas em branco.

Tendo sido registradas as estatísticas descritivas, num segundo momento foi realizado o teste não paramétrico de Kruskal-Wallis para testar a hipótese de as amostras de cada empresa apresentarem diferenças entre si. Conforme Triola (I999), esse teste, também denominado teste H, não exige distribuições normais, o que significa prescindir dos testes de normalidade. Por não terem sido feitos esses testes, assumimos que eventuais violações na normalidade são tratadas como limitações metodológicas da pesquisa. Com a aplicação do teste $\mathrm{H}$ foi possível estabelecer a comparação entre as empresas estudadas no que diz respeito ao nível de concordância quanto à aprendizagem organizacional proporcionada pelo Masp.

Em seguida, com o propósito de medir o grau de associação entre as variáveis, utilizamos o teste não paramétrico de coeficiente de correlação de Spearman, que tem a grande vantagem de testar a hipótese nula de haver correlação sem ter que fazer suposições sobre as populações das quais provêm as amostras (FREUND; SIMON, 2000). Valores desse coeficiente próximos de zero indicam que não existe correlação entre as variáveis; valores próximos de um significam correlação significativa. Isto é, quanto mais próximo de um é o valor do coeficiente, maior é o grau de correlação entre as variáveis. Com essas estatísticas pôde-se chegar aos resultados da próxima seção.

\section{RESULTADOS E DISCUSSÃO}

A apresentação e análise dos dados são realizadas em três subseções. Na primeira, apresentamos a análise estatística, identificando os dados demográficos, com a caracterização dos respondentes e a descrição de quanto o Masp contribui 
para a aprendizagem organizacional. Na segunda subseção, analisamos os dados à luz das reflexões teóricas sobre aprendizado organizacional para, finalmente, delinearmos as implicações teóricas e gerenciais do presente estudo.

\subsection{APRESENTAÇÃO DOS DADOS}

\subsubsection{Dados demográficos}

O número de respondentes caracterizou-se da seguinte forma. Na empresa I, esse número representou $48 \%$ dos respondentes totais. A empresa 2 contribuiu com $30 \%$ dos respondentes, enquanto a empresa 3 representou $22 \%$ do total. Quanto ao tempo em que os respondentes trabalham nas empresas pesquisadas, observou-se que $67 \%$ tinham mais de cinco anos de casa, $47 \%$ utilizavam o Masp pessoalmente e $42 \%$ trabalhavam na empresa havia mais de três anos.

\subsubsection{Masp e as dimensões da aprendizagem organizacional}

Os resultados das análises estatísticas descritivas para os I83 respondentes demonstraram que a média de cada subconstruto da aprendizagem organizacional variou entre 6,4I e 8,77 e o desvio padrão esteve entre I,3 e 2,69 em uma escala de io pontos. Sobre essas medidas, é importante saber o seguinte: quando as médias são elevadas, e os desvios padrão, baixos, isso significa que os respondentes concordam com determinado quesito. Dessa forma, pode-se concluir que o Masp contribui naquela proporção para que a organização aprenda. Porém, se as médias forem baixas, e os desvios padrão, altos, o Masp contribuirá pouco para que a organização aprenda.

No sentido de verificar os maiores e menores resultados, apresentamos nas tabelas a seguir as estatísticas descritivas referentes aos quesitos com maior e menor pontuação nos diversos subconstrutos relevantes para a discussão. A Tabela I apresenta os resultados das estatísticas descritivas dos quesitos com maior e menor pontuação relativos à aquisição de conhecimento. A aquisição de conhecimento é o primeiro subconstruto do modelo de Templeton, Lewis e Snyder (2002) e consiste na coleta de dados e informações necessários para o desenvolvimento dos projetos de melhoria e mudança organizacional. 


\section{TABELA I}

ESTATISTICAS DESCRITIVAS DOS QUESITOS AVALIADOS NA PESQUISA - ITEM AQUISIÇÃO DE CONHECIMENTO

QUESITO

MÉDIA DESVIO

PADRÃO

MÍN. MÁX.

2 - Durante o projeto em que o grupo usa o Masp,

os grupos organizam subgrupos, convidam novos

participantes, alternam lideranças ou fazem outros tipos

$6,53 \quad 2,34 \quad 1 \quad 10$

de arranjos para funcionar melhor.

5 - As causas de problemas são minuciosamente analisadas

e confirmadas com dados antes de qualquer decisão sobre a causa fundamental e as soluções necessárias

$8,20 \quad 1,70 \quad 2 \quad 10$
para eliminá-la.

6 - Normalmente, o monitoramento do desempenho dos processos em que os grupos trabalham já é feito, bastando que os grupos apenas melhorem um indicador

$6,41 \quad 2,53 \quad 1 \quad 10$
já existente.

7 - Os grupos que usam Masp cumprem a etapa 2 observação - atentamente, colhendo o máximo de evidências e elementos antes de analisarem o problema

$8,10 \quad 1,63 \quad 2 \quad 10$
ou definirem planos de ação.

mín. = valor mínimo; máx. = valor máximo.

Fonte: Elaborada pelos autores.

As respostas com mais altos níveis de concordância foram as das questões 5 e 7 relativas à análise minuciosa de causas e coleta de evidências antes da proposição de ações. Isto é, o Masp contribui para que indivíduos e grupos utilizem dados mais estruturados em sua análise. Em outro extremo, na análise dos mais baixos níveis de concordância, estão as questões 6 e 2, relativas ao monitoramento existente e à dinâmica das equipes. Os dados indicam que o Masp tem sido utilizado de forma $a d$ hoc, instituindo controles de melhorias em processos que ainda não eram monitorados. Essas melhorias restringem-se aos limites e às visões dos grupos que as instituem.

A Tabela 2 mostra os resultados dos quesitos relativos à distribuição das informações, que é o segundo subconstruto do modelo de Templeton, Lewis e Snyder (2002), consistindo no compartilhamento de informações entre membros e não membros da equipe do Masp. 
ESTATÍSTICAS DESCRITIVAS DOS QUESITOS AVALIADOS NA PESQUISA - ITEM DISTRIBUIÇÃO DA INFORMAÇÃO

\begin{tabular}{|c|c|c|c|c|}
\hline QUESITO & MÉDIA & $\begin{array}{l}\text { DESVIO } \\
\text { PADRÃOO }\end{array}$ & MíN. & MÁX. \\
\hline $\begin{array}{l}\text { 9- Quando os membros dos grupos procuram } \\
\text { informações e dados sobre problemas, causas e } \\
\text { soluções, eles sabem de sua importância e utilidade } \\
\text { para o sucesso do trabalho. }\end{array}$ & 8,61 & 1,39 & 4 & 10 \\
\hline $\begin{array}{l}10 \text { - Quando estão analisando causas ou buscando } \\
\text { soluções, os grupos de Masp buscam informações e } \\
\text { dados concretos, procurando basear suas decisões em } \\
\text { fatos e dados. }\end{array}$ & 8,61 & 1,30 & 4 & 10 \\
\hline $\begin{array}{l}11 \text { - Os grupos que usam Masp compartilham ou trocam } \\
\text { informações entre si. }\end{array}$ & 6,84 & 2,49 & 1 & 10 \\
\hline
\end{tabular}

mín. = valor mínimo; máx. = valor máximo.

Fonte: Elaborada pelos autores.

Conforme pode ser constatado, as respostas com mais altos níveis de concordância referem-se às questões 9 e Io. Pelos resultados, o Masp, ao menos dentro de seu perímetro de ação, leva os membros a elevado grau de percepção das fontes de informação e de como são importantes para o desenvolvimento de seu trabalho. Quanto à questão de menos concordância - compartilhamento de informações interequipes -, observa-se que o Masp atua de maneira restrita nessa etapa.

Os resultados referentes à interpretação de informações, terceiro subconstruto do modelo de Templeton, Lewis e Snyder (2002), estão na Tabela 3. Essa variável diz respeito à forma como os dados coletados são selecionados, estruturados e analisados pelas equipes para tirar as conclusões necessárias ao desenvolvimento do projeto. As médias das respostas variaram entre 6,45 - eliminação de práticas obsoletas - e 8,77 - uso de ferramentas da qualidade. 
TABELA 3

ESTATÍSTICAS DESCRITIVAS DOS QUESITOS AVALIADOS NA PESQUISA - ITEM INTERPRETAÇÃO DA INFORMAÇÃO

QUESITO MÉDIA DESVIO PADRÃO

MÍN. MÁX.

14 - Os grupos usam ferramentas da qualidade (gráficos, relatórios, planos, modelos de apresentação, software e outras formas comuns de representação) para

$8,77 \quad 1,43 \quad 3 \quad 10$
facilitar a interpretação das informações.

16 - Quando a solução do problema altera substancialmente um procedimento ou rotina, a empresa elimina qualquer referência às práticas antigas

$6,45 \quad 2,44 \quad 1 \quad 10$
e as substitui pelas novas.

17 - Quando a solução adotada pelo grupo envolve uma alteração substancial nas práticas organizacionais, as pessoas assimilam as novidades e alteram seu comportamento no trabalho.

mín. = valor mínimo; máx. = valor máximo.

Fonte: Elaborada pelos autores.

O uso de ferramentas da qualidade (questão I4), além de apresentar baixa variabilidade, foi o quesito de maior pontuação de toda a pesquisa, demonstrando que o uso de ferramentas é bastante utilizado nas empresas. Já as respostas com reduzidos níveis de concordância, as questões I6 e I7, revelam nível relativamente baixo de concordância e alta variabilidade. Isso significa que, nas empresas pesquisadas, as novas propostas advindas da solução de problemas nem sempre são absorvidas, já que os procedimentos obsoletos convivem com os procedimentos atualizados pelas equipes.

A Tabela 4 apresenta os resultados dos quesitos relativos à memória organizacional, que é o último subconstruto do modelo de Templeton, Lewis e Snyder (2002) e que consiste no armazenamento da informação e na memória humana. As médias das respostas variaram entre 7,44 - para o quesito 20 relativo ao repasse de experiência a novos membros - e 7,50 - para o quesito i 8 que retrata a guarda de informações geradas pelas equipes. As médias das respostas aos três quesitos tiveram níveis de concordância e variação medianos em relação às respostas aos demais itens da pesquisa. 
ESTATISTICAS DESCRITIVAS DOS QUESITOS AVALIADOS NA PESQUISA - ITEM MEMÓRIA ORGANIZACIONAL

\begin{tabular}{|lccccc}
\hline QUESITO & MÉDIA & $\begin{array}{c}\text { DESVIO } \\
\text { PADRÃo }\end{array}$ & Mín. & MÁX. \\
\hline $\begin{array}{l}18 \text { - As descobertas feitas durante o processo de solução } \\
\text { do problema são guardadas na forma de documentos } \\
\text { escritos, procedimentos, instruções de trabalho ou } \\
\text { outro tipo de formalização. }\end{array}$ & 7,50 & 2,18 & 1 & 10 \\
\hline $\begin{array}{l}19 \text { - Os empregados se utilizam das informações e do } \\
\text { aprendizado gerado pelos grupos que usam o Masp. }\end{array}$ & 7,46 & 2,15 & 1 & 10 \\
\hline $\begin{array}{l}20 \text { - A experiência obtida pelos membros dos grupos de Masp } \\
\text { durante o projeto de melhoria é repassada às pessoas. }\end{array}$ & 7,44 & 2,07 & 1 & 10 \\
\hline
\end{tabular}

mín. = valor mínimo; máx. = valor máximo.

Fonte: Elaborada pelos autores.

\subsubsection{Testes estatísticos}

Uma vez realizadas as análises descritivas e comparadas conforme consta na Tabela 5, efetuaram-se os testes estatísticos para verificar as similaridades e diferenças da contribuição do Masp para gerar aprendizado organizacional em cada empresa estudada.

\section{TABELA 5}

COMPARATIVO ENTRE EMPRESAS

\begin{tabular}{cccccc}
\hline EMPRESAS & INDICADOR & AQUISIÇÃO & DISTRIBUIÇÃO & INTERPRETAÇÃO & MEMÓRIA \\
\hline \multirow{2}{*}{ Empresa 1 } & Média & 7,28 & 7,69 & 33 & 7,13 \\
& Nesvio padrão & 1,21 & 1,19 & 1,34 & 87 \\
& Média & 7,52 & 8,02 & 7,65 & 7,50 \\
\hline \multirow{2}{*}{ Empresa 2 } & N & 54 & 54 & 54 & 54 \\
& Desvio padrão & 1,14 & 1,24 & 1,23 & 1,67 \\
\hline
\end{tabular}




\section{TABELA 5 (CONClusão)}

COMPARATIVO ENTRE EMPRESAS

\begin{tabular}{cccccc}
\hline \multirow{2}{*}{ EMPRESAS } & INDICADOR & AQUISIÇÃO & DISTRIBUIÇÃO & INTERPRETAÇÃO & MEMÓRIA \\
\hline \multirow{3}{*}{ Empresa 3 } & Média & 7,32 & 7,97 & 7,87 & 8,11 \\
& N & 41 & 41 & 41 & 41 \\
& Desvio padrão & 1,50 & 1,26 & 1,40 & 1,35 \\
\hline \multirow{2}{*}{ Total } & Média & 7,36 & 7,85 & 7,55 & 7,46 \\
& N & 183 & 183 & 182 & 182 \\
& Desvio padrão & 1,26 & 1,22 & 1,33 & 1,81 \\
\hline
\end{tabular}

Fonte: Elaborada pelos autores.

Pelos resultados do teste de Kruskal-Wallis registrados na Tabela 6, notamos que as variáveis aquisição do conhecimento, distribuição e interpretação da informação não apresentaram diferenças estatisticamente significantes $(\mathrm{p}<0,05)$. Portanto, concluímos que há homogeneidade dos efeitos do Masp sobre a aprendizagem organizacional quanto às fases da aquisição do conhecimento, distribuição e interpretação da informação.

\section{TABELA 6}

SIGNIFICÂNCIA ASSINTÓTICA OBTIDA

PELO TESTE DE KRUSKAL-WALLIS

\begin{tabular}{ccccc} 
& AQUISIÇÃO & DISTRIBUIÇÃO & INTERPRETAÇÃO & MEMÓRIA \\
\hline Significância & 0,395 & 0,179 & 0,075 & 0,018 \\
\hline
\end{tabular}

Fonte: Elaborada pelos autores.

O subconstruto da memória organizacional apresentou grau de concordância diferenciado nas três empresas estudadas $(\mathrm{p}<0,05)$, com diferenças representativas entre as empresas. A Tabela 7 torna possível visualizar as médias por questão, em cada empresa pesquisada. Os resultados apresentam altos níveis de concordância na empresa 3 para todas as questões do subconstruto memória organizacional, o que parece demonstrar mais preocupação dessa empresa em relação à manutenção do conhecimento gerado. 


\section{MÉDIAS DAS EMPRESAS PESQUISADAS - ITEM MEMÓRIA ORGANIZACIONAL}

\begin{tabular}{lcccc}
\hline QUESITO & EMPR1 & EMPR2 & EMPR3 \\
\hline $\begin{array}{l}18 \text { - As descobertas feitas durante o processo de solução do problema } \\
\text { são guardadas na forma de documentos escritos, procedimentos, } \\
\text { instruções de trabalho ou outro tipo de formalização. }\end{array}$ & 7,49 & 7,13 & 8,03 \\
\hline $\begin{array}{l}19 \text { - Os empregados se utilizam das informações e do aprendizado } \\
\text { gerado pelos grupos que usam o Masp. }\end{array}$ & 6,99 & 7,69 & 8,15 \\
\hline $\begin{array}{l}\text { 20 - A experiência obtida pelos membros dos grupos de Masp } \\
\text { durante o projeto de melhoria é repassada às pessoas. }\end{array}$ & 6,95 & 7,68 & 8,12 \\
\hline
\end{tabular}

Fonte: Elaborada pelos autores.

O último teste buscou correlacionar as variáveis dos quatro subconstrutos, mediante o coeficiente de Spearman, cujos resultados são mencionados na Tabela 8. Observa-se que o coeficiente de Spearman exibe correlação positiva entre todas as variáveis. O subconstruto mais correlacionado com os demais foi o de memória organizacional. E o menos correlacionado foi o relativo à aquisição de conhecimento.

\section{TABELA 8}

COEFICIENTE DE CORRELAÇÃA DE SPEARMAN ENTRE SUBCONSTRUTOS

\begin{tabular}{lcccc} 
& AQUISIÇÃO & DISTRIBUIÇÃO & INTERPRETAÇÃO & MEMÓRIA \\
\hline Aquisição & 1,000 & 0,487 & 0,493 & 0,419 \\
\hline Distribuição & 0,487 & 1,000 & 0,640 & 0,668 \\
\hline Interpretação & 0,493 & 0,640 & 1,00 & 0,602 \\
\hline Memória & 0,419 & 0,668 & 0,602 & 1,000 \\
\hline
\end{tabular}

Fonte: Elaborada pelos autores.

\subsection{ANÁLISE E DISCUSSÃO DOS DADOS}

Pelos resultados apresentados na seção anterior, chegamos à conclusão geral de que o Masp contém intrinsecamente práticas que favorecem todas as 
dimensões da aprendizagem organizacional. Entretanto, há limitações quanto aos efeitos desse aprendizado, principalmente no que diz respeito ao tipo de aprendizagem obtido. O Masp parece favorecer mais o aprendizado de laço simples. Visando proceder ao detalhamento e à reflexão desses achados, são feitas a seguir quatro grandes considerações sobre os efeitos do Masp na aprendizagem organizacional.

A consideração de número I refere-se à relativização da experiência direta propiciada pelo Masp. A segunda e terceira considerações abordam a natureza do aprendizado, mediante a discussão da dinamização da aprendizagem e do tipo de aprendizado obtido. Por fim, a quarta consideração contempla a influência do Masp na memória organizacional.

\subsubsection{Consideração $n^{0}$ 1: a relativização da experiência direta}

Essa consideração está embasada principalmente no subconstruto aquisição de conhecimento (Tabela I). Os dados dessa tabela mostram que a utilização do Masp permite que as empresas se valham de uma análise minuciosa de causas e coleta de evidências antes da proposição de ações de mudança. Essa objetividade propiciada pelo Masp significa que esse método tende a contribuir para o aprendizado fundamentado na racionalidade instrumental (MILLER, I996).

Tal racionalidade busca adequar meios a fins com o propósito de relativizar ou minimizar os efeitos que os valores pessoais exercem na análise de dada situação. Ao proporcionar tal racionalidade, o Masp parece proteger as organizações do que é na literatura conhecido como armadilhas da experiência (HUBER, I99I) ou armadilhas da competência (LEVITT; MARCH, I99I). Essas armadilhas estão presentes nas organizações que consideram a experiência direta de seus gestores ou funcionários como as fontes mais adequadas para propor e acionar redefinições de rotinas. Huber (I99I) adverte que o aprendizado baseado exclusivamente na experiência direta é limitado e deve ser enriquecido por mecanismos intencionais.

Conforme sugerem os dados desta pesquisa (Tabela I), a utilização de um método racional de análise, como o Masp, tem a vantagem de propor a relativização da experiência direta, ao mesmo tempo que parte dessa experiência. Nesse sentido, o Masp contribui para uma reflexão dirigida às práticas cotidianas em que problemas emergem e devem ser solucionados.

\subsubsection{Consideração $n^{\circ}$ 2: dinamização da aprendizagem}

Essa consideração se apoia nos subconstrutos da aquisição, distribuição e interpretação da informação (tabelas I, 2 e 3). Observamos que as questões com 
menor média também tiveram maior desvio padrão. Essa constatação leva a crer que as empresas pesquisadas não exploram suficientemente a possibilidade de alternâncias que venham a dinamizar a composição de membros ou de lideranças (questão 2 da Tabela I). Além disso, não enfatizam em grau mais elevado o compartilhamento de informações interequipes (questão II da Tabela 2).

A exposição a novas ideias e o compartilhamento de informações, embora sejam práticas importantes do ponto de vista da aprendizagem, demonstraram ser adotados nas empresas avaliadas apenas como troca de experiências sobre problemas afins ou sobre o aprendizado no método em si. Nesse sentido, podemos concluir que o Masp deu mostras de gerar aprendizado apenas de laço simples. Isso significa que exclusivamente a lógica do método parece não ser suficiente para fomentar aprendizados mais profundos e desencadear prontamente mudanças de comportamento (questões i6 e I7 da Tabela 3).

É plausível supor que fontes de conhecimento interno estejam constrangidas e tal constrangimento resulte de fatores contextuais, seja da organização, seja da aplicação do método propriamente dito, como o gerenciamento das equipes. Trabalhos anteriores, como os de Tucker, Edmondson e Spear (200I), reconhecem que nem sempre a resolução de problemas de maneira sistemática é capaz de desenvolver aprendizado organizacional de laço duplo.

\subsubsection{Consideração $n^{0} 3$ : tipos de aprendizado}

Essa consideração continua a discutir os tipos de aprendizado sustentados pelo Masp, com base mais especificamente no subconstruto da interpretação da informação (Tabela 3 e testes estatísticos). Apesar de ser reconhecido o papel do Masp no aprendizado de laço simples, os dados revelaram que as novas rotinas instituídas não substituem definitivamente as rotinas antigas (as questões I6 e I7 da Tabela 3 tiveram menores médias e maior desvio padrão).

O curioso é que, metodologicamente, o Masp contempla fases de desaprendizado, por conter uma etapa de padronização posterior à solução de problemas em si. Assim, contraditoriamente, percebemos certa fragilidade do Masp em gerar a institucionalização do conhecimento. Talvez essa fragilidade não esteja relacionada às etapas dessa metodologia, mas seja decorrente das dificuldades em gerenciar ciclos de descongelamento e de congelamento de conhecimento, ou seja, em lidar com a quantidade excessiva de informações. Conforme bem relatado por Huber (I99I), a coexistência de informação demasiada tende a congestionar os canais de acesso aos sistemas interpretativos.

Mesmo o Masp permitindo aos indivíduos a reflexão sobre suas experiências e práticas passadas e, por consequência, a mudança das rotinas, os resultados aferidos nesta pesquisa sugerem que tal mudança se efetiva dentro de certos limites 
(coeficiente de Spearman). Podemos conjecturar que os fatores extrínsecos ao método, como o contexto organizacional e o gerenciamento das equipes, representem esses limites e venham a atuar como variáveis intervenientes ou mediadoras do Masp na aprendizagem organizacional. Concluímos que a contribuição do Masp para a aprendizagem organizacional não ocorre de forma direta, mas é um efeito que pode ser obtido se algumas condições forem satisfeitas, principalmente as ligadas ao contexto organizacional e à dinâmica de aplicação do método.

\subsubsection{Consideração $n^{0}$. 4: memória organizacional}

Essa consideração apoia-se, sobretudo, no subconstruto da memória organizacional (tabelas 4 e 7), nos testes de Kuskal-Wallis e no coeficiente de Spearman. Os dados revelam a importância do Masp na memória organizacional. Contudo, as diferenças significativas encontradas no subconstruto da memória organizacional (teste de Kuskal-Wallis) entre as empresas parecem demonstrar mais preocupação da empresa 3 em relação à manutenção de conhecimento gerado quando comparada com as empresas i e 2. Esse resultado reafirma a nossa suposição em relação à possibilidade de o contexto estar exercendo efeitos intervenientes ou moderadores na aprendizagem organizacional.

A memória foi o construto mais correlacionado com os demais (coeficiente de Spearman), o que demonstra a sua influência no processo como um todo. Cabe ressaltar que a memória não tem local específico, mas está distribuída em diferentes partes, como nos locais físicos, indivíduos, protocolos e cultura. Entretanto, quando tal estoque se torna coeso demais, a aceitação total do passado como provedor de sentido torna-se uma frente ameaçadora, pois raramente passam a ser observados os novos aspectos do ambiente (WEICK, I973). Portanto, torna-se importante que as organizações questionem as lições do passado (WEICK, 2004).

A aquisição do conhecimento é uma atividade que tende, teoricamente, a promover esse questionamento. Contudo, tal construto foi o que menos apresentou correlação positiva com os demais. Esse resultado sugere que os efeitos do Masp dependem muito mais de como a informação é compartilhada e interpretada do que propriamente dos dados sobre os quais se está trabalhando. Assim chama atenção, mais uma vez, para a importância do gerenciamento de equipes, um dos fatores que parecem interferir no tipo de aprendizado propiciado.

\section{IMPLICAÇÕES TEÓRICAS E PARA A PRÁTICA GERENCIAL}

As análises, conclusões e considerações aqui realizadas identificam pelo menos duas importantes implicações teóricas e gerenciais para a perspectiva 
da aprendizagem organizacional. Do ponto de vista teórico, este trabalho, ao concluir que o Masp contribui para todas as dimensões da aprendizagem organizacional, embora dentro de certos limites, reforça a ideia de introduzir práticas normativas de melhorias contínuas para fomentar processos de mudanças organizacionais.

Essa ideia tem sido corroborada por diversos resultados de pesquisas. No Brasil, Oprime, Monsanto e Donadone (20I0), por exemplo, concluem que programas de melhoria contínua têm evoluído e contribuído para o aprendizado organizacional, recomendando sua utilização. Também Gonzalez e Martins (2OII) constatam como os programas de melhoria são válidos para gerar aprendizagem organizacional.

Nesse sentido, este trabalho coaduna-se a esses estudos e ratifica a perspectiva técnica ou gerencial da aprendizagem (ELKJAER, 200I; DIBELLA; NEVIS, I998), a qual defende a necessidade de se desenvolverem habilidades cognitivas dos indivíduos para que possam reestruturar seu pensamento no sentido de visualizar com mais clareza os fenômenos que impactam as organizações. Essa defesa, entretanto, não significa rechaçar a perspectiva das práticas situadas, reforçando a artificialidade da dicotomia existente entre essas diferentes abordagens.

Os resultados aqui obtidos reforçam as recentes publicações, como a de Marshall (2008), que refuta a incomensurabilidade entre as perspectivas cognitivas e das práticas situadas em aprendizagem. Esse autor argumenta que a incompatibilidade dessas duas perspectivas tem sido superdimensionada, desprezando a contribuição recíproca que cada uma delas oferece à outra. Como exemplo, mostra particularmente o papel dos frameworks cognitivos em desvendar realidades mediante o processo de sense-making. Os resultados da presente pesquisa são congruentes com esse exemplo, uma vez que o Masp deu mostras de promover a reflexão e a construção de uma visão comum aos indivíduos ao exigir mais objetividade na análise dos problemas.

Do ponto de vista empírico, a importância deste estudo para a prática gerencial parece clara. Ao dar dicas de que os resultados do Masp tendem a se limitar ao aprendizado de laço simples, esta investigação sugere que, quando as empresas utilizam tal metodologia, devem explorar mais o seu potencial de gerar aprendizados mais profundos. Segundo Oprime, Monsanto e Donadone (2010), essa possibilidade é efetivada quando programas de melhoria são absorvidos em uma perspectiva estratégica. Ou, segundo Gonzalez e Martins (20II), quando sustentados por uma cultura que valorize a autonomia dos indivíduos em sua condução.

Para isso, empresas devem instituir estruturas mais maleáveis na aplicação do Masp (WITT, 2002), flexibilizando papéis, alternando membros e organizando as equipes de forma que aumentem a variedade interna. Isto é, o Masp, para se 
tornar em oportunidade de aprendizado (SOUZA, 2004) de laço duplo, deve ser enriquecido com práticas que exponham os indivíduos a mais variedade de situações e ideias, bem como práticas que promovam mais compartilhamento e troca de conhecimento interequipes. Com a adoção desses mecanismos parece haver mais possibilidades de que as metodologias de solução de problemas de maneira sistemática visem a resultados em esferas mais abrangentes do que aquelas exclusivas de melhorias nos procedimentos operacionais.

\section{CONCLUSÃO}

Este trabalho teve por objetivo avaliar em que medida o Masp, um método de análise sistemática de solução de problemas, contribui para a aprendizagem organizacional. Os resultados revelaram contribuições significativas em todas as dimensões da aprendizagem organizacional. Especialmente permite a reflexão dirigida às práticas cotidianas, favorecendo a mudança de rotinas e comportamentos no ambiente de trabalho.

Entretanto, o tipo de aprendizado propiciado tende a se restringir ao aprendizado de laço simples, em detrimento do de laço duplo. Cabe destacar que as novas rotinas incorporadas não substituem definitivamente as antigas. Portanto, concluímos que há dificuldades do Masp em gerar a institucionalização de novos conhecimento, bem como aprendizado de laço duplo. Fatores extrínsecos ao método, tais como o contexto organizacional e o gerenciamento de equipes, parecem atuar como variáveis mediadoras para que o Masp desencadeie aprendizados mais profundos.

Em que pese a importância dessas conclusões, é importante assinalar que são originadas de um estudo com algumas fragilidades metodológicas. A fragilidade mais evidente refere-se ao fato de que os resultados aqui obtidos se restringem às empresas pesquisadas, não podendo ser generalizados para outras populações. Acrescenta-se a eliminação da variável tempo do foco de análise feita. Sabe-se que o tempo de utilização de determinada prática formal, como é o caso do Masp, pode influenciar nos efeitos por ele produzidos. Outro ponto a ser destacado é que nesta investigação não foram formuladas relações de causalidade.

Pesquisas mais robustas do ponto de vista dos testes estatísticos poderiam aprofundar as descobertas aqui sugeridas. Por exemplo, testando hipóteses sobre as condições nas quais a utilização do Masp possui mais efeito no aprendizado organizacional. Desse modo, sugerimos que pesquisas futuras busquem dirimir tais fragilidades no sentido de avançar os estudos sobre práticas formais na geração da aprendizagem organizacional. 


\section{LEARNING IN ORGANIZATIONS TRIGGERED BY FORMAL PRACTICES IN WORK ENVIRONMENT}

\section{ABSTRACT}

This article aims to assess the degree to which formal practices introduced in work environment contribute to organizational learning. The theoretical background recognizes that companies adapt to the environmental by individual knowledge absorption in collective properties. This knowledge is incorporated in organizational practices. At the moment companies deal to changing environmental they need to exploit current resources, explore new ones and turn into their practices. Such flow is called by organizational learning. The systematic problem-solving method is considered as one of most recommended formal practices to promote organizational learning. However if the one side there is the valuation of such method on the other hand the literature needs its critical evaluation. In other words, there are a few empirical evidences that assess the real contribution of this method to promote organizational learning. Thus there is a gap between recommendation for its use and theoretical underpinning of such suggestion. This article asks in what measure the systematic problem-solving method contribute to organizational learning. This question is important to highlight its effects over the organizations that employ it. Thus the research focus on Masp, one of the systematic problem-solving method more release in Brazil. To do so, it was considered that organizational learning is composed by four dimensions: knowledge acquisition, information distribution, information interpretation, and organizational memory. It was conducted a survey with three different organization. The analyses have been focused on how Masp is related to the four dimension of organizational learning. More specifically, it was identified what dimension and the type of organizational learning that are supported by Masp. The statistical tests pointed out that the using of Masp contributed to learning at all organizational dimension, such as knowledge acquisition, information distribution, information interpretation, and organizational memory. However, this learning was restricted to corrections in routines, which means that the method itself was not able to trigger learning at deeper levels. In reality, the depth of learning seemed to be correlated to the contextual factors in organizations.

\section{KEYWORDS}

Organizational learning; Formal practices of learning; Masp; Systematic methods of problem-solving; Learning in work environment. 


\section{LA APRENDIZAJE DE LAS ORGANIZACIONES GENERADA POR LAS PRÁCTICAS FORMALES EN EL LUGAR DE TRABAJO}

\section{RESUMEN}

Este artículo tiene como objetivo evaluar el grado en que las prácticas formales establecidas en el lugar de trabajo contribuye al aprendizaje organizacional. Para este análisis se eligió el método de análisis de la resolución sistemática de problemas, considerado en la literatura como una de las prácticas más recomendadas. Por un lado, está la exaltación de un método para generar el aprendizaje, por el contrario, la literatura sufre su evaluación crítica. Es decir, se observa que hay escasez de investigación empírica que tiene por objeto determinar la contribución real del método para promover el aprendizaje organizacional. Por lo tanto, existe una brecha entre las recomendaciones y que la teoría de tales recomendaciones. Este artículo al preguntar hasta qué punto los métodos de resolución sistemática de problemas contribuyen al aprendizaje organizacional tiene la principal contribución aclarar los efectos de estos métodos a las organizaciones que lo utilizan. Así que se centró el Masp, uno de los métodos de resolución sistemática de problemas más extendida en Brasil y en el extranjero. Para hacer esta evaluación es parte del marco teórico del aprendizaje organizacional se compone de cuatro dimensiones: la adquisición de conocimientos, de distribución y la interpretación de la información y la memoria de la organización. Demostró teóricamente la tesis de que el Masp es uno de los mecanismos que generan el aprendizaje en todas las dimensiones de la organización que tratan de comprobar empíricamente, a través de una encuesta cuantitativa con tres organizaciones diferentes. Los análisis estadísticos mostraron que el uso del Masp contribuye a todos los niveles de aprendizaje organizacional. Sin embargo este aprendizaje a menudo se tiende a limitarse a las reparaciones de rutina, lo que significa que el uso del método en sí no es capaz de generar un aprendizaje más profundo. La profundidad del aprendizaje parece correlacionarse con más fuerza con los factores contextuales en las organizaciones.

\section{PALABRAS CLAVE}

Aprendizaje organizacional; Prácticas formales de aprendizaje; Masp; Método de resolución sistemática de problemas; Aprendizaje en lugar de trabajo. 


\section{REFERÊNCIAS}

ALVAREZ, R. R. Desenvolvimento de uma análise comparativa de métodos de identificação, análise e solução de problemas. I996. I89 f. Dissertação (Mestrado em Engenharia de Produção)-Universidade Federal do Rio Grande do Sul, Porto Alegre, I996.

ANTONELLO, C. S. Articulação da aprendizagem formal e informal: seu impacto no desenvolvimento de competências gerenciais. Alcance, Itajaí, v. I2, n. 2, p. I83-209, maio/ago. 2005.

ARGYRIS, C.; SCHÖN, D. A. Organizational learning: a theory of action perspective. Harlow: Addison-Wesley, I978.

CAMPOS, V. F. TQC: controle da qualidade total (no estilo japonês). 8. ed. Belo Horizonte: INDG, 2004. $256 \mathrm{p}$.

CASEY, A. Enhancing individual and organizational learning. Management Learning, v. 36, n. 2, p. I3I-I47, June 2005 .

CASEY, A. J.; GOLDMAN, E. J. Enhancing the ability to think strategically: a learning model. Management Learning, v. 4I, n. 2, p. I67-I85, Apr. 2010.

CHILD, J. Organizational learning. In: CHILD, J.; FAULKNER, D. Cooperative strategy. London: Oxford University Press, I997.

CHIVA, R.; ALEGRE, J. Organizational learning and organizational knowledge: towards the integration of two approaches. Management Learning, v. 36, n. I, p. 49-68, Mar. 2005.

DEMING, W. E. Qualidade: a revolução da administração. Rio de Janeiro: Saraiva, I990.

DIBELLA, A.; NEVIS, E. C. How organizations learn: an integrated strategy for building learning capability. San Francisco: Jossey Bass, I998.

ELKJAER, B. Em busca de uma teoria de aprendizagem social. In: SMITH, M. E. et al. Aprendizagem organizacional e organização de aprendizagem: desenvolvimento na teoria e na prática. São Paulo: Atlas, 200I. p. Iо0-II6.

FREUND, E. J.; SIMON, A. G. Estatística aplicada. Porto Alegre: Bookman, 2000.

GARVIN, D. A. Building a learning organization. Harvard Business Review, Boston, v. 7I, n. 4, p. 78-9I, July/Aug. I993.

GHERARDI, S. Practice-based theorizing on learning and knowing in organizations. Organizations, v. 7, n. 2, p. 2II-223, May 2000.

GOMES, J. F. A terceira competência: um convite a revisão do seu modelo de gestão. Rio de Janeiro: Qualitymark, 2004.

GONZALEZ, R. V. D.; MARTINS, M. F. Melhoria continua e aprendizagem organizacional: múltiplos casos em empresas do setor automobilístico. Gestão \& Produção, São Carlos, v. I8, n. 3, p. 473-486, $201 \mathrm{I}$.

GRANT, R. M. Toward a knowledge-based theory of the firm. Strategic Management Journal, Chichester, v. I7, p. I09-122, 1996.

GUERRA, R. S. Gestão do conhecimento e gestão pela qualidade: uma análise comparativa a partir da experiência de uma grande empresa brasileira. Belo Horizonte: C/Arte, 2002.

HEDBERG, B. How organizations learn and unlearn? In: NYSTROM, P. C.; STARBUCK, W. H. (Ed.). Handbook of organizational design. London: Oxford University Press, I981. p. 8-27. 
HOSOTANI, K. The QC problem solving approach: solving workspace problems the japanese way. Tokio: 3A Corporation, I992.

HUBER, G. P. Organizational learning the contributing process and the literatures. Organization Science, Providence, v. 2, n. I, p. 88-II5, Feb. I99I.

HUYSMAN, M. Contrabalançando tendenciosidades: uma revisão crítica da literatura sobre aprendizagem organizacional. In: SMITH, M. E. et al. Aprendizagem organizacional e organização de aprendizagem: desenvolvimento na teoria e na prática. São Paulo: Atlas, 200I. p. 83-95.

KETELHÖHN, W. Out with tollboxes, in with thinking. Industrial and Commercial Training, Guilsborough, v. 27, n. I0, p. 29-30, I995.

KIM, D. The link between individual and organizational learning. Sloan Management Review, Boston, v. 35, p. 37-50, Fall i993.

KUME, H. Statistical methods for quality improvement. Tokyo: 3A Corporation, I992.

LEONARD-BARTON, D. The factory as a learning laboratory. Sloan Management Review, v. 34, n. I. p. 23-38, Fall I992.

LEVITT, B.; MARCH, J. G. Organizational learning. Organization Science, Providence, v. 2, n. I, p. 88-9I, I99I.

MAGALHÃES, H. P. Uma investigação sobre métodos para solução de problemas na ótica da engenharia: análise da teoria e da prática. 2005. Dissertação (Mestrado em Engenharia de Produção)-Universidade Federal de Minas Gerais, Belo Horizonte, 2005.

MARSHALL, N. Cognitive and practice-based theories of organizational knowledge and learning: incompatible or complementary? Management Learning, v. 39, n. 4, p. 4I3-435, Sept. 2008.

MARTÍNEZ-LEÓN, I. M.; MARTÍNEZ-GARCÍA, J. A. The influence of organizational structure on organizational learning. International Journal of Manpower, London, v. 32, n. 5, p. 537-566, 2011. MARTINS, M. B. O processo de aprendizagem organizacional no âmbito de programas de qualidade. 2002. Dissertação (Mestrado em Administração)-Universidade Federal do Rio Grande do Sul, Porto Alegre, 2002.

MILLER, D. A preliminary typology of organizational learning: synthesizing the literature. Journal of Management, Stillwater, v. 22, n. 3, p. 485-505, June I996.

MIRVIS, P. H.; MARYLAND, S. S. Historical foundations of organization learning. Journal of Organizational Change Management, Bradford, v. 9, n. I, p. 13-31, I996.

NICKOLS, F. Choosing the right problem solving approach. Distance Consulting. 2004. Disponível em: <http://www.nickols.us/choosing.pdf>. Acesso em: I2 maio 2007.

NONAKA, I.; TAKEUCHI, H. Criação de conhecimento na empresa: como as empresas japonesas geram a dinâmica da inovação. I7. ed. Rio de Janeiro: Campus, I997.

NONAKA, I.; TOYOAMA, R.; NAGATA, A. A firm as a knowledge-creating entity: a new perspective on the theory of the firm. Industrial and Corporate Change, Oxford, v. 9, n. I, p. I-20, Mar. 2000. OPRIME, P. C.; MONSANTO, R.; DONADONE, J. C. Análise da complexidade, estratégias e aprendizagem em projetos de melhoria contínua: estudos de caso em empresas brasileiras. Gestão \& Produção, São Carlos, v. I7, n. 4, p. 669-682, 2010.

ORIBE, C. Y. Quem resolve problemas aprende? A contribuição do método de análise e solução de problemas para a aprendizagem organizacional. 2008. Dissertação (Mestrado de Administração)Pontifícia Universidade Católica de Minas Gerais, Belo Horizonte, 2008. 
PARKER, G. W. Structured problem solving: a parsec guide. Hampshire: Gower, I995.

PAWLOWSKY, P. The treatment of organizational learning in management science. In: DIEKERS, M. et al. Handbook of organizational learning and knowledge. Oxford: Oxford University Press, 2003. p. 6I-88.

PERPÉTUO, M. A.; TEIXEIRA, F. Há espaço para métodos de identificação, análise e solução de problemas (MIAPSs) nas organizações, mesmo diante da racionalidade limitada, da intuição e das heurísticas? Organizações \& Sociedade, Salvador, v. 8, n. 2I, p. I59-I74, maio/ago. 200 I.

PRANGE, C. Aprendizagem organizacional: desesperadamente em busca de teorias? In: SMITH, M. E. et al. Aprendizagem organizacional e organização de aprendizagem: desenvolvimento na teoria e na prática. São Paulo: Atlas, 200I. p. 4I-60.

SALVIATO, S. Uma metodologia de solução de problemas com enfoque na aprendizagem organizacional: um estudo de caso aplicado no Besc. I999. Dissertação (Mestrado em Engenharia de Produção)-Universidade Federal de Santa Catarina, Florianópolis, I999.

SANTOS-VIJANDE, M. L.; LÓPEZ-SANCHEZ, J. Á.; TRESPALACIOS, J. A. How organizational learning affects a firm's flexibility, competitive strategy and performance. Journal of Business Research, New York, v. 65, n. 8, p. 1079-1089, Aug. 2012.

SCHOLTES, P. Times da qualidade: como usar equipes para melhorar a qualidade. 2. ed. Rio de Janeiro: Qualitymark, 2002.

SCOTT, W. R. Organizations, rational, natural and open systems. New Jersey: Prentice Hall, I998.

SMITH, G. F. Too many types of quality problems. Quality Progress, Winsconsin, v. 33, n. 4, p. 43-49, Apr. 2000.

SMITH, M. E.; ARAUJO, L. Aprendizagem organizacional: oportunidades e debates atuais. In: SMITH, M. E. et al. Aprendizagem organizacional e organização de aprendizagem: desenvolvimento na teoria e na prática. São Paulo: Atlas, 200I. p. I5-34.

SOUZA, S. Y. Organizações de aprendizagem ou aprendizagem organizacional. RAE-Eletrônica, São Paulo, v. 3, n. I, jan./jun. 2004.

SPENDER, J. C. Making knowledge the basis of a dynamic theory of the firm. Strategic Management Journal, Chichester, v. I7. p. 45-62, I996.

TAKAHASHI, A. R. W.; FISCHER, A. L. Debates passados, presentes e futuros da aprendizagem organizacional - um estudo comparative entre a produção acadêmica nacional e internacional. Revista de Administração Mackenzie, São Paulo, v. Io, n. 5, p. 53-76, set./out. 2009. Disponível em: $<$ http://www3.mackenzie.br/editora/index.php/RAM>. Acesso em: 2I mar. 20 Io.

TEMPLETON, G. F.; LEWIS, B. R.; SNYDER, C. A. Development of a measure for the organizational learning construct. Journal of Management Information Systems, New York, v. I9, n. 2, p. I752I8, Fall 2002.

TRIOLA, F. M. Introdução à estatística. 7. ed. Rio de Janeiro: LTC, I999.

TUCKER, A.; EDMONDSON, A.; SPEAR, S. Why your organization isn't learning all it should. Harvard Business Week, p. 4, 30 July $200 \mathrm{I}$.

VERSIANI, Â. F.; FISCHER, A. L. A aprendizagem organizacional como um campo específico de conhecimento no cenário dos estudos organizacionais. Economia e Gestão, Belo Horizonte, v. 8, n. I8, p. IO-3I, out. 2008. Disponível em: <http://periodicos. pucminas.br/index.php/economiaegestao/ article/view/315/321>. Acesso em: is abr. 2010. 
WEICK, K. A psicologia social da organização. São Paulo: Edgard Blucher, I973.

WEICK, K. Aprendizagem organizacional: confirmando um oxímoro. In: CLEGG, S. R. et al. Handbook de estudos organizacionais: ação e análise organizacionais. São Paulo: Atlas, 2004. p. 36I-388.

WITT, H. C. Aprendizado organizacional a partir do ensino da metodologia de análise e solução de problemas. 2002. Dissertação (Mestrado Profissional em Engenharia - Modalidade Profissionalizante)-Universidade Federal do Rio Grande do Sul, Porto Alegre, 2002. 